\section{Medí̈al Seienę}

pISSN 2321-7359; eISSN 2321-7367

\section{The role of bright and dark} personality traits in self and other protective pandemicrelated preventive behaviors

\author{
Parastoo Naeimijoo ${ }^{1}$, Ahmad Yousefi ${ }^{2}$, Abbas Masjedi \\ Arani $^{3 凶}$, Mostafa Heidari ${ }^{4}$, Reza Karimi ${ }^{5}$, Maryam \\ Aslzaker Lighvan $^{6}$
}

Naeimijoo P, Yousefi A, Arani AM, Heidari M, Karimi R, Lighvan MA. The role of bright and dark personality traits in self and other protective pandemic-related preventive behaviors. Medical Science, 2022, 26, ms25e1941.

doi: https://doi.org/10.54905/disssi/v26i119/ms25e1941

\section{Author Affiliation:}

'Student Research Committee, (Department of Clinical Psychology, school of medicine), Shahid Beheshti University of Medical Sciences, Tehran, Iran; Email: pnaeimijoo1392@gmail.com 2Student Research Committee, (Department of Clinical Psychology, school of medicine), Shahid Beheshti University of Medical Sciences, Tehran, Iran; Email: ahmadyousefi7676@gmail.com

${ }^{3}$ Associate professor, Department of Clinical Psychology, school of medicine, Shahid Beheshti University of Medical Sciences, Tehran, Iran; E-mail: dr.masjediarani@gmail.com

${ }^{4}$ Assistant professor, Department of psychology, Islamic Azad University, Garmsar Branch, Garmsar, Iran; Email: dr.heidari20sh@gmail.com

${ }^{5}$ Department of Clinical Psychology, school of medicine, Shahid Beheshti University of Medical Sciences, Tehran, Iran; Email:

rezakarimi127@yahoo.com

${ }^{6}$ Assistant professor, Department of Clinical Psychology, school of medicine, Shahid Beheshti University of Medical Sciences, Tehran, Iran; Email: m.aslzaker@sbmu.ac.ir

Corresponding author

Associate professor, Department of Clinical Psychology, school of medicine, Shahid Beheshti University of Medical Sciences, Tehran, Iran; E-mail: dr.masjediarani@gmail.com

Peer-Review History

Received: 05 December 2021

Reviewed \& Revised: 06/December/2021 to 5/January/2022

Accepted: 7 January 2022

Published: 14 January 2022

Peer-review Method

External peer-review was done through double-blind method.

URL: https://www.discoveryjournals.org/medicalscience

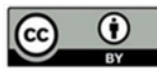

This work is licensed under a Creative Commons Attribution 4.0 International License.

\section{DISCOVERY} SCIENTIFIC SOCIETY

Copyright $@ 2022$ Discovery Scientific Society.

\begin{abstract}
Aim: The Purpose of this study was to examine the relationship between bright and dark aspects of personality dimensions and self-interest and other interest preventive related behaviors during Covid-19 pandemic. Method: This cross-sectional study was advertised on social media. 541 participants completed four self-reported questionnaires through the online link. Analysis was performed to assess the kind of association by SPSS. Results: Findings indicate different significant associations between the personality dimensions and preventive behaviors. Regression analysis indicated that conscientiousness $(\mathrm{B}=.27, \mathrm{P}=.00)$ and agreeableness $(\mathrm{B}=.11, \mathrm{P}=.03)$ positively and extraversion $(B=-.14 \quad P=.02)$ negatively predict self-protective behaviors. Likewise, conscientiousness $(\mathrm{B}=.40, \mathrm{P}=.00)$ and agreeableness $(\mathrm{B}=.14, \mathrm{P}=.00)$ and antisocial tendencies $(B=-.23, P=.00)$ could have predictive role in otheroriented behaviors. Conclusion: Personality traits have role in explaining compliance and noncompliance with Covid-19 guideline protocols and protecting self and others.
\end{abstract}

Keywords: Personality; Covid-19 Pandemic; Preventive Behaviors; SelfProtective; other protective

\section{INTRODUCTION}

With the emergence of a novel infectious disease, COVID-19, the world has been rocked by a severe crisis. One of the countries being adversely affected is Iran (Shahriarirad et al., 2020). The alarming rate of mortality and ascending rapid spread led the government to impose quarantine and strict mandatory containment measures in order to mitigate the spread of disease. However, there are massive differences in the ways people deal with restrictions and deploy pandemic-related preventive behaviors (PRPB). PRPB are efforts to reduce the spread of the infection and encompass prosocial behaviors like social distancing, disinfecting or antisocial behaviors like hoarding supplies in case of shortage (Oosterhoff \& Palmer, 2020a). 
A series of recent studies have tried to explain why some individuals are more willing to comply with the policies while others remain disinclined to follow the constraints. In the search of psychological correlates contributing to adherence to rules, several factors have been attested in recent studies such as risk perception (Abdelrahman, 2020), demographic factors (Park et al., 2020), Optimism-pessimism (Jovančević \& Milićević, 2020), and personality dimensions (Volk et al., 2021; Zajenkowski et al., 2020). Among these factors, Personality traits have been remarkably linked to health behaviors and following or violating PRPB. For instance, agreeableness and extraversion were shown to be negatively associated with behavioral protection and personal hygiene practices, while, conscientiousness and neuroticism were positively linked to engagement with hand-washing and social distancing (Carvalho et al., 2020).We posit that PRPB in the context of a pandemic could be divided into two broad categories: self-protective and other-protective. It is fully recognized that self-protection during the COVID-19 pandemic is of paramount importance to avoid infection (Matias et al., 2020), though the adoption of prosocial behaviors vs. self-interest values should not be ignored.

High rates of incidence and mortality bear this implication that only self-directed preventive behaviors (hand washing and disinfecting) may not suffice in assuaging the contagion and adopting other-focused behaviors (self-isolation in case of illness, mouth covering while sneezing, sharing in a supply shortage, restraining news distribution from invalid resources) and considering how one's action entails consequences for others, should be attended by people. In the search of the role of personality traits in other-oriented PRPB, we have encountered vast and stable differences in individuals' concern for their own vs. others' welfare (Ashton et al., 2014). So far, some studies have been conducted on the relation between personality differences and PRPB, however, most have assessed preventive behaviors by a single or few items in a broad manner and to the best of our knowledge none has drawn a specific distinction between self and other protective behaviors.

We believe that assessing PRPB entails detailed questions. Hence, we conducted a survey to investigate the association and potential predictive role of dark and bright personality traits contributions to self and other protective PRPB.

\section{METHOD}

\section{Procedure}

This study was advertised on various social media platforms (telegram channels, WhatsApp channel, Instagram) during the 4th peak from 5th April to May 15th, 2021. Participants self-selected into the study were informed of the nature of the study and the anonymity of their responses in a paragraph and were given a link to scales. A total number of 584 questionnaires were filled among which 43 were excluded due to partial incompletion. Inclusion criteria were age range between 18 to 65 ; Ability to read and write; having access to the internet.

\section{Ethical approval}

The study procedure, methodology, and questionnaires were in accordance with and approved by the ethical standards of [ViceChancellor in Research Affairs - Shahid Beheshti University of Medical Sciences (Ethics approval number: IR.SBMU.RETECH.REC.1399.1044). Upon the completion of a series of self-report measures, all individuals involved in the study provided informed consent online, via a tick box, indicating that they had read and understood upon being debriefed.

\section{Measurements}

Demographic

Demographics included sex, age, education level were measured using self-report instrumentation.

\section{NEO Personality Inventory (NEO-FFI)}

Individual differences in the Big Five traits were measured with the Personality scale NEO-FFI consisting of 60 questions and 5 personality dimensions (neuroticism, extraversion, openness, agreeableness, and conscientiousness). Questions are answered on a 5-point Likert scale from "Not at all like me" to "extremely like me." Internal consistency between 0.68 to 0.86 (McCrae \& Costa, 1987) and test-retest reliability has been obtained from 0.86 to 0.9 for five factors (McCrae \&John, 1992). Psychometric investigations of this scale in Iran show Cronbach's alpha 0.86, 073, 0.56, 0.68, and 0.87 for neuroticism, extraversion, openness, agreeableness, and conscientiousness respectively (Farshi \& Tabatabei, 2001).

\section{Dirty Dozen scale (DDS)}

Dirty Dozen scales were used to measure a constellation of three socially undesirable personality traits: narcissism, psychopathy, and Machiavellianism (Shahriarirad et al., 2020). The scale consists of 12 items assessing individual differences in dark aspects of 
personality. Each aspect is assessed by 4 items on a 7 point-Likert scale ranging from 1 (strongly disagree) to 7 (strongly agree). Developers of the scale (2010) reported high validity of Cronbach's alpha (.83). Test-retest reliability was .89 for the total scale and.76 to .87 for the three subscales. The internal consistency of the subscales was 0.76 for psychopathy, 0.72 for Machiavellianism, and 0.77 for narcissism in the Iranian population (Jonason \& Webster, 2010).

Pandemic-related preventive behavior (PRPB)

A questionnaire used by Oosterhoff (2020) was adapted and translated to Persian. The English version constitutes 4 dimensions: disinfecting (4 items), social distancing (5 items), hoarding ( 1 item), news monitoring (1 item). The Cronbach's alpha above .60 for subscales indicates good internal consistency (Oosterhoff B \& Palmer, 2020b).

Other protective pandemic- related preventive behavior (OPPRPB)

We created 11 items each measuring behaviors and routine decisions with specific considerations of others' health and safety. The analysis show Cronbach's alpha (.87) of the instrument in this study. In assessing construct validity, the confirmatory factor analysis revealed standard coefficient of all questions on main factor are significant showing that the questionnaire has an acceptable construct validity.

\section{RESULT}

The number of participants in the present study was 541 with an age range of 18 to 65 years $(\mathrm{M}=32.45)$, about half (81\%) of whom were female and (19\%) were male. Demographic characteristics of the participants are listed in table 1.

\begin{tabular}{|l|l|l|l|}
\hline \multicolumn{2}{|l|}{ Table 1 demographic variables } \\
\hline variables & status & frequency & Percentage \\
\hline \multirow{3}{*}{ sex } & Female & 438 & 81 \\
\cline { 2 - 4 } & Male & 103 & 19 \\
\hline \multirow{4}{*}{ Marital status } & Single & 293 & 54.2 \\
\cline { 2 - 4 } & Married & 248 & 45.8 \\
\hline \multirow{4}{*}{ Educational level } & Diploma and sub- diploma & 12 & 2.2 \\
\cline { 2 - 4 } & Associate Degree & 89 & 16.5 \\
\cline { 2 - 4 } & Bachelor & 318 & 58.8 \\
\cline { 2 - 4 } & MA & 93 & 17.2 \\
\cline { 2 - 4 } & PhD and above & 29 & 5.4 \\
\hline
\end{tabular}

Chi-square test was used in order to investigate the effects of demographic characteristics on self (Disinfecting, Social distancing, News monitoring) and other protective PRPB (Hoarding and other oriented questions). Findings show that among the demographic variables, only the effect of gender is significant on other-oriented behaviors. According to the median, women caring behaviors are more than men $(\operatorname{men}=43.62$, women $=47.33)$. The effect of other demographic characteristics was not significant on either self or other-protective behaviors (Table 2).

\begin{tabular}{|c|c|c|c|c|}
\hline \multicolumn{5}{|c|}{$\begin{array}{l}\text { Table } 2 \text { Chi-square test to examines the effect of demographic } \\
\text { characteristics on self-care and other-care behaviors }\end{array}$} \\
\hline \multirow{2}{*}{ variables } & \multicolumn{2}{|c|}{ self-protective } & \multicolumn{2}{|c|}{ other-protective } \\
\hline & Chi-square & Sig. & Chi-square & Sig. \\
\hline $\operatorname{sex}$ & 41.12 & 0.08 & 50.3 & 0.17 \\
\hline Marital status & 37.4 & 0.16 & 61.94 & 0.02 \\
\hline Educational level & 125.65 & 0.34 & 149.01 & 0.85 \\
\hline
\end{tabular}

Pearson correlation coefficient was used (Table 3). The findings show that regarding other-protective PRPB among bright personality traits, conscientiousness, agreeableness, neuroticism, and extraversion have a significant positive correlation while dark 
triad traits have significant negative correlation. It was found that hoarding has significant positive correlation with dark all triad and negative association with agreeableness and openness. Regarding news monitoring, the data suggest that only conscientiousness has a positive significant relation with PRPB. The positive link between neuroticism, conscientiousness and agreeableness is evident with disinfecting while a negative link between openness and extraversion and Machiavellianism. The correlation analysis shows that all dark triad personality and among five factors extraversion traits are negatively associated with social distancing.

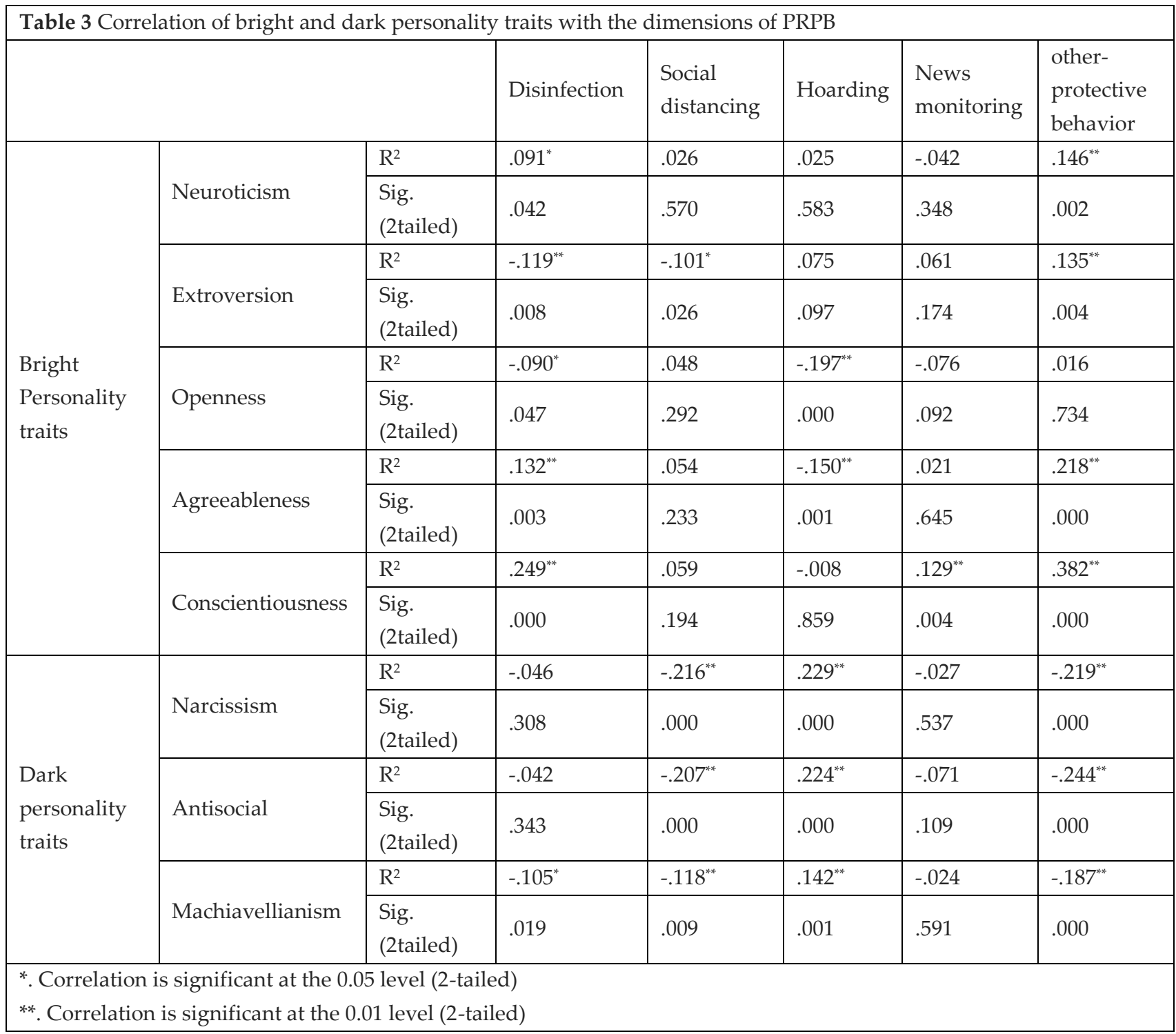

According to the appropriate correlation coefficients of light and dark personality traits with self and other PRPB, in order to evaluate the predictive role of each of the regression personality traits, the relationship between these factors was also examined (Table 4).

\begin{tabular}{|c|c|c|c|c|}
\hline Regression Models & $\mathrm{R}$ & $\mathrm{R}^{2}$ & $\mathrm{~F}$ & Sig. \\
\hline $\begin{array}{l}\text { Prediction of self-protective behaviors } \\
\text { via bright personality traits }\end{array}$ & 0.26 & 0.071 & 6.68 & 0.001 \\
\hline $\begin{array}{l}\text { Prediction of other-protective } \\
\text { behaviors via bright personality traits }\end{array}$ & 0.40 & 0.16 & 15.84 & 0.001 \\
\hline
\end{tabular}




\begin{tabular}{|l|l|l|l|l|}
\hline $\begin{array}{l}\text { Prediction of self-protective behaviors } \\
\text { via dark personality traits }\end{array}$ & 0.17 & 0.029 & 4.85 & 0.002 \\
\hline $\begin{array}{l}\text { Prediction of other-protective } \\
\text { behaviors via dark personality traits }\end{array}$ & 0.27 & 0.075 & 12.23 & 0.001 \\
\hline
\end{tabular}

Findings show that in the prediction of other PRPB based on bright and dark personality traits, all four regression models are significant and the highest predictive power is related to other-oriented behaviors based on bright personality traits, particularly conscientiousness (figure 1). Similarly, high correlation of conscientiousness and self-directed PRPB is also shown (figure 2). While regarding the dark aspects of personality this high correlation is related to antisociality which is in negative trend (figure 3 ). Regarding In order to investigate the effect of each personality trait in predicting other-protective behaviors, their coefficients are examined in Table 5 .

\begin{tabular}{|c|c|c|c|c|c|c|}
\hline \multicolumn{2}{|l|}{ Model } & \multicolumn{2}{|c|}{$\begin{array}{l}\text { Unstandardized } \\
\text { Coefficients }\end{array}$} & \multirow{2}{*}{$\begin{array}{l}\begin{array}{l}\text { Standardized } \\
\text { Coefficients }\end{array} \\
\text { Beta }\end{array}$} & \multirow{2}{*}{$\mathrm{T}$} & \multirow{2}{*}{ Sig. } \\
\hline \multirow{9}{*}{$\begin{array}{l}\text { Self-protective } \\
\text { behaviors }\end{array}$} & & B & Std. Error & & & \\
\hline & Neuroticism & .023 & .052 & .026 & .436 & .663 \\
\hline & Extroversion & -.114 & .047 & -.148 & -2.444 & .025 \\
\hline & Openness & -.060 & .061 & -.046 & -.980 & .328 \\
\hline & Agreeableness & .125 & .060 & .111 & 2.095 & .037 \\
\hline & Conscientiousness & .230 & .049 & .271 & 4.707 & .000 \\
\hline & Narcissism & .023 & .196 & .013 & .115 & .908 \\
\hline & Antisocial & -.163 & .124 & -.103 & -1.310 & .191 \\
\hline & Machiavellianism & -.180 & .129 & -.106 & -1.396 & .163 \\
\hline \multirow{8}{*}{$\begin{array}{l}\text { Other-protective } \\
\text { behaviors }\end{array}$} & Neuroticism & .068 & .078 & .051 & .870 & .385 \\
\hline & Extroversion & -.129 & .071 & -.108 & -1.821 & .069 \\
\hline & Openness & -.043 & .093 & -.021 & -.459 & .646 \\
\hline & Agreeableness & .243 & .090 & .141 & 2.691 & .007 \\
\hline & Conscientiousness & .524 & .074 & .404 & 7.117 & .000 \\
\hline & Narcissism & .150 & .299 & .053 & .504 & .615 \\
\hline & Antisocial & -.588 & .192 & -.237 & -3.056 & .002 \\
\hline & Machiavellianism & -.338 & .198 & -.127 & -1.702 & .089 \\
\hline
\end{tabular}

Findings show that extraversion $(\mathrm{B}=-.14 \mathrm{P}=.02)$, agreeableness $(\mathrm{B}=.11, \mathrm{P}=.03)$, and conscientiousness $(\mathrm{B}=.27$, $\mathrm{P}=.00)$ predict selfprotective behaviors, implyinghighly extraverted individuals show low self-protective PRPB while, conscientious and agreeable ones show the most self-oriented PRPB. Meanwhile, agreeableness $(B=.14, P=.00)$, conscientiousness - $(B=.40, P=.00)$, antisocial $(B=-$ .23, $\mathrm{P}=.00)$ predict-protective behaviors.

Data scatter chart in the correlation between conscientiousness and self-protective PRPBs shows that data scattering tends to be positive. The density of scatter points at high scores of both variables indicates a high correlation between conscientiousness and self and other protective PRPBs. The data scatter plot in the correlation between antisocial behaviors and other protective PRPBs tends to be negative. 


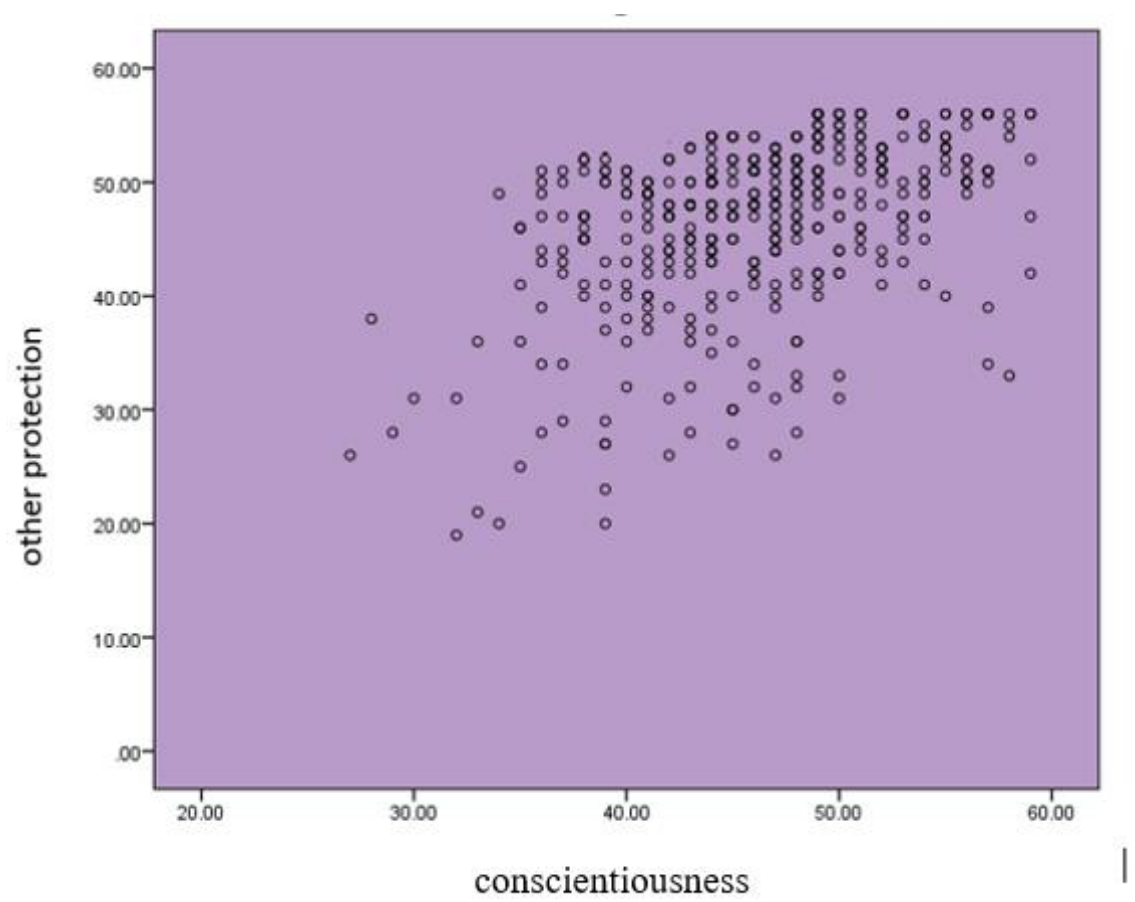

Figure 1 Scatter plot between other-protective behaviors and conscientiousness

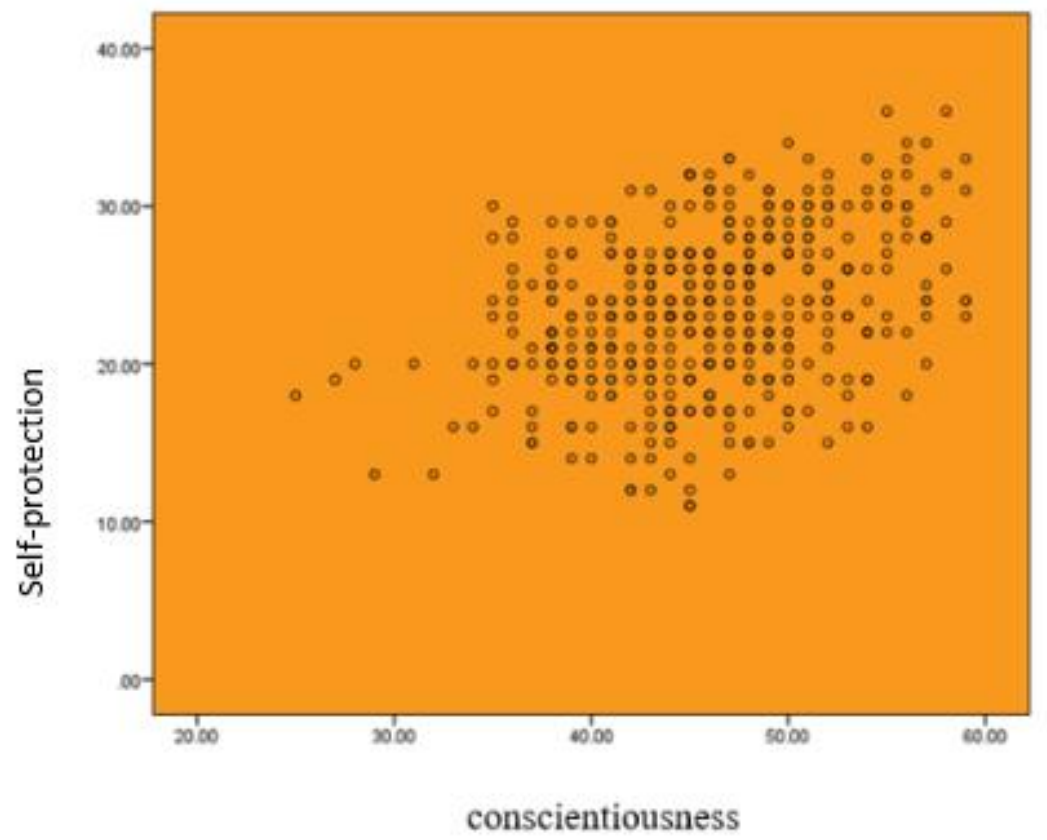

Figure 2 Scatter plot between self-protective behaviors and conscientiousness 


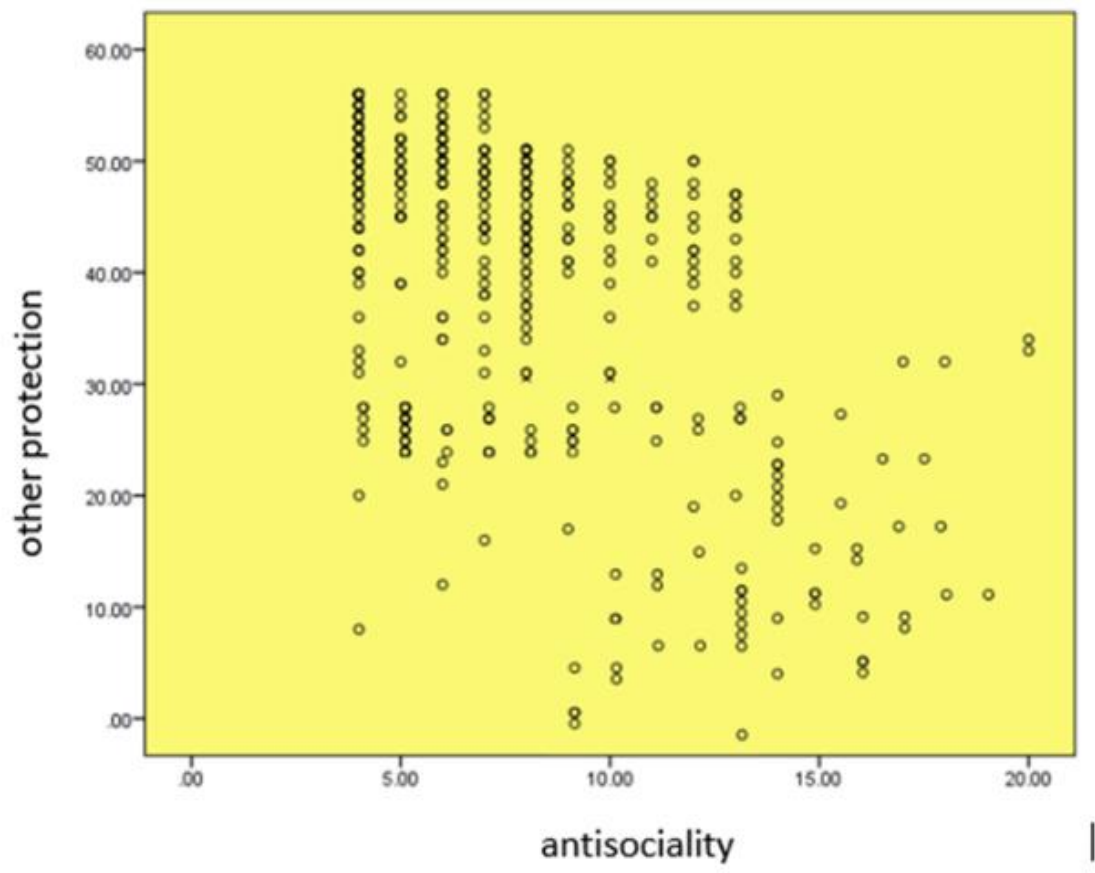

Figure 3 Scatter plot between other-protective behaviors and antisociality

\section{DISCUSSION}

Our study extends previous research by examining the unique contribution of personality traits on adaptive and maladaptive behavioral performance related to Covid-19 guidelines. Overall, the results show a substantial variation in the way people uphold protective practices and this heterogeneity is widely related to both dark and bright personality aspects.

\section{Other protective PRPB}

Trying to investigate the predictive power of associated variables in explaining other protective behaviors, we found that Consciousness and antisocial was a plausible determinant. The robust predictive value of conscientiousness in other-oriented behaviors, highlight the trend of conscientious individuals as being meticulous, respectful to social norms and rules, and being alert to the need of others (Carvalho et al., 2020). This means that in the pandemic era, this moral character puts others' interests as a priority, deploys morality, and move toward collective responsibility for the sake of all who are at risk of being inflicted (If I feel pseudo-Covid-related symptoms, I self-isolate and inform the ones who had recently been in contact with me even if I am not certain of being inflicted). This goes in accordance with studies relating conscientiousness to protective behaviors of reducing risk and health behaviors.

Agreeableness was also revealed as a significant predictor. In explaining the finding, the conceptualization of agreeableness can be considered. As being kind, helpful, good-natured, sympathetic, and cooperative are the main characteristic of an agreeable individual (Abdelrahman, 2020; Park et al., 2020). It is lightly probable that agreeable individuals be self-interested actors in society, instead they show caring, compassionate attitudes. Thus, in pandemic time they act prosocially and try to help the community to have a role in slowing down the spread of the virus, rather than selfishly violating social norms. Prior studies also related altruistic tendencies, group cooperation, and helping behaviors to agreeableness (karimzade \& besharat, 2011; Graziano et al., 2007).

In contrast to agreeable and conscientious individuals exhibiting prosocial behavior, results show that those with high scores on dark personality aspects specifically those with antisocial tendencies, are less obliged to engage in other protective behaviors regarding the highest predictive role of antisocial facet in other-protective PRPB. It is clear that the antisocial individuals pursue their own goals and perceive their activities more important than others' safety. Several aspects of dark triad demonstrating lack of concern for others, and moral disengagement (Jonason et al., 2015), may be responsible: Non-empathetic social attitudes (psychopathy), self-centeredness and lacking a sense of bond (narcissism), manipulating others (Machiavellianism) (Paulhus \& Williams, 2002), do not allow the self- absorbed person to focus on others' welfare, hence sees no point in adopting hygienic measures for the sake of saving others' lives. This is in line with studies asserting community feelings and narcissism as two opposite phenomena (Kałużna-Wielobób et al., 2020). 


\section{Hoarding}

Dark aspects of human nature are associated with hoarding behavior. Dark personality sides are not expected to see the need of others in the time of stress and judge whether one's action has harmful effects or not. The rivalrous attitude, need for power and superiority, insufficient collective empathy, and feelings of entitlement lead to being blind to others' need and a subsequent move against benevolence principals such as sharing or donating. Therefore, in urgent times full of shortage, the individual neglects others in favor of his own gains and rushes to accumulate rare supplies. This aligns with the notion of the dark triad as an exploitative social strategy (Paulhus \& Williams, 2002). In fact, based on what Reed (2003) asserts a strong moral identity discourages self-interested behavior such as hoarding (Reed \& Aquino, 2003). Previous studies have similarly shown that greater social responsibility is associated with less hoarding (Oosterhoff \& Palmer, 2020b). These findings duly explain why hoarding behavior is negatively related to agreeableness and openness. Tendency to be altruistic, trustworthy, and useful (karimzade \& Besharat, 2011) makes an agreeable one compassionate enough to care for others and refrain accumulating while others are also in need. This is in keeping with the notion implicating agreeableness as a prosocial personality (Habashi et al., 2016). Moreover, those with openness are known to be receptive to new experiences and preferences for variety. Thus, an open individual may highly be tolerant McCrae, 1996) and does not panic to buy excessive supplies even in the crisis. Furthermore, low tendency for social dominance in open individual (Duckitt \& Sibley, 2007) gives rise to less rivalry with others to over acquire supplies in shortage times.

\section{Self- protective PRPB}

\section{News monitoring}

Unlike previous studies which have shown the relevance of neuroticism, only conscientiousness was associated with greater news monitoring in this study. This may be related to the information needs and social responsibility of a conscientious individual, not a safety-seeking behavior. That is by tracking the news, the person is informed of the extent of the risk and global status to forewarn himself and adopt cautionary actions to battle Coronavirus. In other words, news monitoring could serve as a regulatory strategy.

\section{Social distancing}

The only factor of bright aspect, related to social distancing was extraversion which was in a negative trend. Extraversion is reflective of having an inclination to be sociable, energetic, talkative, outgoing, and having high levels of activity. People with a high score of extraversions are typically prone to social proximity and closeness all of which affect the extraverted to disregard the advised Covid-19 recommendations (Abdelrahman, 2020). Because of their more reward-seeking tendencies (Smillie, 2013), and high dopamine release responsible for behavioral exploration (De Young, 2014; Wacker \& Smillie, 2015); following social distancing measures, including limiting physical contact, being home-bound, avoiding travel, and maintaining a 2-meter distance would be over-burdening for an extraverted. These findings are congruent with studies showing lower engagement of extraverts in social distancing (Carvalho, 2020; Abdelrahman, 2020).

What is worth noting here is the negative relation of dark personality traits with social distancing and. This is in accordance with a study by reporting Machiavellian individuals neglect personal care and social distancing and avoidance behavior related to hygiene, such as washing their hands or avoiding touching nose. The results gained about Machiavellianism perfectly duplicates findings of Tiberti et al., (2021) when considering disinfecting. This could be explained by inherent characteristics such as impulsivity and aggressive conducts adversely affecting adaptive responses and leading to disrespecting Covid-induced restrictions with protesting manner because being in a harmony, wrenches their sense of omnipotence and invulnerability as a study duly reported these individuals tend to lives in pandemic time their lives as nothing happened. Recent studies have also shown more engagement of these individuals in risky behaviors, unhealthy life style and low life expectancy (Jonason et al., 2015; Crysel et al., 2013).

\section{Disinfecting}

We found the positive association of neuroticism. Along with what has been reported in evidence about the role of neuroticism in avoiding risk (Meshram et al., 2017), results showed a positive association. This was predictable as neuroticism is known by a proclivity to avoid risks and developing anxious feelings (Jonason \& Sherman, 2020), leading neurotic individuals to practice pandemic measures to protect themselves against viruses and increase their sense of safety. The positive association of conscientiousness, agreeableness, and negative link of extraversion with disinfecting was also shown. Data of regression analysis 
likewise showed the predictive role of conscientiousness in both other and self- protective PRPB. Extraversion and agreeableness could only predict self-oriented PRPB.

These are consistent with the research reporting negative link with extraversion to infectious diseases (Abdelrahman, 2020), and positive association of conscientiousness with more engagement in hand washing, social distancing and general and personal hygiene practices like (Carvalho, 2020; Garbe et al., 2020). These trends support the definition of conscientiousness encompassing self-control, planning, cautious and compliance with rules (McCrae \& Costa, 2008). Therefore, people who score high for this trait are already have predisposition to duty commitment, are goal-oriented and have powerful determination (Jensen-Campbell et al., 2002). In the pandemic time frame, thus rule-following is not challenging as they are already good planners and adapt to stressful situations logically, pandemic hygienic rituals are not a problem for a person who strives for accuracy and perfection in their tasks. Additionally, referring to previous studies, conscientious individuals visit a relatively small number of places during a day, therefore, restrictions, such as isolation, might be not so disturbing for them (Ai et al., 2019).

The same pattern exists about the role of agreeableness. This characteristic is known as the ability to get along and adopt constructive actions (Ehrler et al., 1999). Moreover, compliance as an aspect of agreeableness is a typical response to conflict. Generalized disposition of an agreeable person to have greater compliance and perceive more duty enables him to comply with hygienic guidelines like disinfecting. Similarly, Mortensen (2010), reported that agreeable people have greater avoidance of infections (Mortensen et al., 2010). Alike social distancing, it was found that adoption of disinfecting and self- protective PRPB was lower among extraverted people. This might be related to typical characteristic of extraversion which is not resonant to Covid guidelines. Stimulation seeking and enthusiasm to engage with others along with impulsive tendencies found in an extraverted person (Carlo et al., 2005), do not allow him to self-control and plan behavior in a ritualistic way. Earlier studies in the same manner, reported that such characteristics greatly influence extravertedreadiness to engage with hand hygiene recommendations (Carvalho et al., 2020).

Another worthy finding of the study is that the degree of compliance differs among males and females particularly in otheroriented PRPB in that female group showed more caring behaviors. This could be explained to more feminine traits probably, because the trend of socialization in female is to educate them to be better caregivers as Annandale \& Hunt, (1990) believe that masculine traits cause perceiving less obligation to protect others and the communities. This goes parallel with findings revealing a higher responsible attitude and level of compliance in women (Allington \& Dhavan, 2020).

\section{Limitation and future research direction}

As the current study provides insights into role of personality in heterogeneous PRPB, the conclusion must be interpreted within the context of some limitations. First, reliance of the study findings on cross-sectional data should be noticed. People may respond differently during different phases of pandemic. Other studies needed to resolve this issue. Second, we only included basic aspects of personality. The potential role of other personality facets like optimism, perfectionism etc. or other situational factors like risk perception could be addressed in future research. Third, the nature of the study entailed the undertaking correlation and regression analysis, investigating the casual relations in future longitudinal studies would be beneficial. Fourth, data collection was solely provided through online links thus those who had no or limited access to internet remained unexplored. Addressing this issue would be a good opportunity for future researchers.

\section{CONCLUSIONS}

In conclusion, this study suggests that personality traits are important predictors of peoples' compliance pattern to health measures and protecting others. This means that including personality traits into health research and practice is a promising way for public health campaigns when trying to foster obligatory health messages. Public health policy makers need to consider and emphasize these aspects of psychology to tailor measurements in accordance to personality traits in order to enhance the immediate compliance and encourage other protective altruistic behaviors and implement strategies that address the factors related to antisocial traits.

\section{Acknowledgement}

This study is related to project NO 1399/63421. From Student Research Committee, Shahid Beheshti University of Medical Sciences, Tehran, Iran. We also appreciate the "Student Research Committee" and "Research \& Technology Chancellor" in Shahid Beheshti University of Medical Sciences for their financial support of this study. 


\section{Authors' Contributions}

Conceptualization - Ahmad Yousefi and Parastoonaeimijoo; methodology - Ahmad Yousefi and Parastoonaeimijoo; software Reza Karimi; validation - Ahmad Yousefi and Reza Karimi; formal analysis - Reza Karimi; investigation, Ahmad Yousefi; resources - Parastoonaeimijoo; data curation - Mostafa, Heidari; writing-original draft preparation - Parastoonaeimijoo; writing-review and editing - Ahmad Yousefi; supervision - Maryam, Aslzaker Lighvan; project administration - Abbas Masjedi Arani; funding acquisition - Ahmad Yousefi. All authors have read and agreed to the published version of the manuscript.

\section{Research funding}

The research leading to these results received funding from [Student Research Committee, Shahid Beheshti University of Medical Sciences, Tehran, Iran] under Grant Agreement No [1399/63421]. The Shahid Beheshti University had no further role in study design; data collection, analysis, and interpretation of data; in the writing of the report; and in the decision to submit the paper for publication.

\section{Conflict of interests}

The authors declare that there are no conflicts of interests.

\section{Data and materials availability}

All data associated with this study are present in the paper.

\section{REFERENCES AND NOTES}

1. Abdelrahman M. Personality traits, risk perception, and protective behaviors of Arab residents of Qatar during the COVID-19 pandemic. Int J Ment Health Addict 2020; 18(3):112.

2. Ai P, Liu Y, Zhao X. Big Five personality traits predict daily spatial behavior: Evidence from smartphone data. Pers Indiv Differ 2019; 147:285-91.

3. Allington D, Dhavan N. The relationship between conspiracy beliefs and compliance with public health guidance with regard to COVID-19. London: Centre for Countering Digital Hate; 2020. pp 10-30.

4. Annandale E, Hunt K. Masculinity, femininity and sex: an exploration of their relative contribution to explaining gender differences in health. Sociol Health Illn 1990; 12(1):24-46.

5. Ashton MC, Lee $\mathrm{K}$, De Vries RE. The HEXACO honestyhumility, agreeableness, and emotionality factors: A review of research and theory. J Pers Soc Psychol 2014; 18(2):139-52.

6. Carlo G, Okun MA, Knight GP, de Guzman MRT. The interplay of traits and motives on volunteering: Agreeableness, extraversion and prosocial value motivation. Pers Indiv Differ 2005; 38(6):1293-305.

7. Carvalho LdF, Pianowski G, Gonçalves AP. Personality differences and COVID-19: are extroversion and conscientiousness personality traits associated with engagement with containment measures? Trends Psychiatry Psychother 2020; 42(2):179-84.

8. Crysel LC, Crosier BS, Webster GD. The Dark Triad and risk behavior. Pers Indiv Differ 2013; 54(1):35-40.

9. DeYoung C. Openness/Intellect: A dimension of personality reflecting cognitive exploration. In: Cooper ML, Larsen RJ, Medical Science, 26, ms25e1941 (2022)
eds.APA handbook ofpersonality and social psychology. Washington, DC: American Psychological Association 2014; pp369-99.

10. Duckitt J, Sibley CG. Right wing authoritarianism, social dominance orientation and the dimensions of generalized prejudice. Eur J Pers 2007; 230.

11. Ehrler DJ, Evans JG, McGhee RL. Extending Big-Five theory into childhood: A preliminary investigation into the relationship between Big-Five personality traits and behavior problems in children. Psychol Schools 1999; 36(6):451-8.

12. Farshi MM, A. Tabatabei, M. The application and investigation of new Neo test and its construct among Iranian students. Alzahra j 2001; 11(39):173-198.

13. Garbe L, Rau R, Toppe T. Influence of perceived threat of Covid-19 and HEXACO personality traits on toilet paper stockpiling. Plos one 2020; 15(6):232-4

14. Graziano WG, Habashi MM, Sheese BE, Tobin RM. Agreeableness, empathy, and helping: A person $\times$ situation perspective. Journal of personality and social psychology J Pers Soc Psychol 2007; 93(4):583.

15. Habashi MM, Graziano WG, Hoover AE. Searching for the prosocial personality: A Big Five approach to linking personality and prosocial behavior. Pers Soc Psychol Bull 2016; 42(9):1177-92.

16. Jensen-Campbell LA, Rosselli M, Workman KA, Santisi M, Rios JD, Bojan D. Agreeableness, conscientiousness, and effortfulcontrol processes. J Res Pers 2002; 36(5):476-89.

17. Jonason PK, Baughman HM, Carter GL, Parker P. Dorian Gray without his portrait: Psychological, social, and 
physicalhealth costs associated with the Dark Triad. Pers Indiv Differ 2015; 78:5-13.

18. Jonason PK, Sherman RA. Personality and the perception of situations: The Big Five and Dark Triad traits. Pers Indiv Differ 2020; 163:110081.

19. Jonason PK, Strosser GL, Kroll CH, Duineveld JJ, Baruffi SA. Valuing myself over others: The Dark Triad traits and moral and social values. Pers Indiv Differ 2015; 81:102-6.

20. Jonason PK, Webster GD. The dirty dozen: a concise measure of the dark triad. Psycholassess 2010; 22(2):420.

21. Jovančević A, Milićević N. Optimism-pessimism, conspiracy theories and general trust as factors contributing to COVID19 related behavior-A cross-cultural study. Pers Indiv Differ 2020; 167: 110-216

22. Kałużna-Wielobób A, Strus W, Cieciuch J. Community Feeling and Narcissism as Two Opposite Phenomena. Front Psychol 2020; 11:21-6.

23. Karimzade A, besharat ma. An investigation of the relationship between personality dimensions and stress coping styles. Procd Soc Behv 2011; 30:797-802.

24. Matias T, Dominski FH, Marks DF. Human needs in COVID-19 isolation. J Health Psychol 2020; 25(7):871-82.

25. McCrae RR, Costa Jr PT. The five-factor theory of personality. The Guilford Press; 2008. 2008. pp 159-81

26. McCrae RR, Costa PT. Validation of the five-factor model of personality across instruments and observers. J Pers Soc Psychol 1987; 52(1):81.

27. Mc Crae RR, John OP. An introduction to the five-factor model and its applications. J Pers 1992; 60(2):175-215.

28. McCrae RR. Social consequences of experiential openness. Psychol Bull 1996; 120(3):323.

29. Meshram S, Gattani D, Shewale A, Bodele S. Association of personality traits with oral health status: a cross-sectional study. Int J Indian Psychol 2017; 4(2);61.

30. Mortensen CR, Becker DV, Ackerman JM, Neuberg SL, Kenrick DT. Infection breeds reticence: The effects of disease salience on self-perceptions of personality and behavioral avoidance tendencies. Psychol Sci 2010; 21(3):440-7.

31. Oosterhoff B, Palmer CA. Attitudes and psychological factors associated with news monitoring, social distancing, disinfecting, and hoarding behaviors among US adolescents during the coronavirus disease 2019 pandemic. JAMA pediatrics 2020; 174(12):1184-90.

32. Park CL, Russell BS, Fendrich M, Finkelstein-Fox L, Hutchison M, Becker J. Americans' COVID-19 stress, coping, and adherence to CDC guidelines. J Gen Intern Med 2020; 35(8):2296-303.

33. Paulhus DL, WilliamsKM. The dark triad of personality: Narcissism, Machiavellianism, and psychopathy. J Res Pers 2002; 36(6):556-63.
34. Reed IA, Aquino KF. Moral identity and the expanding circle of moral regard toward out-groups. J Pers Soc Psychol 2003; 84(6):1270-86.

35. Shahriarirad R, Khodamoradi Z, Erfani A, Hosseinpour H, Ranjbar K, Emami Y, Mirahmadizadeh A, Lotfi M, Shirazi Yegane B, Dorraninejad A, Hemmati A, Ebrahimi M, Moghadami M. Epidemiological and clinical features of 2019 novel coronavirus diseases (COVID-19) in the South of Iran. BMC infectious diseases 2020; 20(1):1-12.

36. Smillie LD. Extraversion and reward processing. Curr Dir Psychol Sci 2013; 22(3):167-72.

37. Triberti S, Durosini I, Pravettoni G. Social distancing is the right thing to do: Dark Triad behavioral correlates in the COVID-19 quarantine. Pers Indiv Differ 2021; 170:1104.

38. Volk AA, Brazil KJ, Franklin-Luther P, Dane AV, Vaillancourt T. The influence of demographics and personality on COVID-19 coping in young adults. Pers Indiv Differ 2021; 168:110398.

39. Wacker J, Smillie LD. Trait extraversion and dopamine function. Soc Personal Psychol Compas s2015; 9(6):225-38.

40. Zajenkowski M, Jonason PK, Leniarska M, Kozakiewicz Z. Who complies with the restrictions to reduce the spread of COVID-19? Personality and perceptions of the COVID-19 situation. Pers Indiv Differ 2020; 166:110-99. 